Case Report

\title{
Polyneuropathy as Novel Initial Manifestation in a Case of "Nonsecretory" POEMS Syndrome with Sjögren's Syndrome
}

\author{
Minrui Liang, ${ }^{1,2}$ Zhixing Jiang, ${ }^{1,2}$ Zhiguang Lin, ${ }^{3}$ Bobin Chen, ${ }^{3}$ Hejian Zou, ${ }^{1,2}$ \\ Weiguo Wan, ${ }^{1,2}$ and Jun Liu ${ }^{4}$ \\ ${ }^{1}$ Division of Rheumatology, Huashan Hospital, Shanghai, China \\ ${ }^{2}$ Institute of Rheumatology, Immunology and Allergy, Fudan University, Shanghai 200040, China \\ ${ }^{3}$ Department of Hematology, Huashan Hospital, Fudan University, Shanghai 200040, China \\ ${ }^{4}$ Nursing Department, Huashan Hospital, Fudan University, Shanghai 200040, China
}

Correspondence should be addressed to Weiguo Wan; wgwan1969@sina.com and Jun Liu; huashanliujun@aliyun.com

Received 9 July 2016; Revised 21 September 2016; Accepted 12 October 2016; Published 4 January 2017

Academic Editor: Arduino A. Mangoni

Copyright (C) 2017 Minrui Liang et al. This is an open access article distributed under the Creative Commons Attribution License, which permits unrestricted use, distribution, and reproduction in any medium, provided the original work is properly cited.

\begin{abstract}
POEMS syndrome (polyneuropathy, organomegaly, endocrinopathy, monoclonal gammopathy, and skin changes) is a paraneoplastic syndrome driven by plasma cell dyscrasias. We report a patient with novel initial manifestation of polyneuropathy, which was considered due to Sjögren's syndrome but with poor response to methylprednisolone $(120 \mathrm{mg} / \mathrm{d})$ and intravenous immunoglobulin (IVIg). Further investigation by imaging tests and following biopsy eventually confirmed the diagnosis of POEMS syndrome secondary to solitary plasmocytoma. To our knowledge, this is the first reported case of POEMS syndrome with Sjögren's syndrome occurring in the absence of a peripheral monoclonal gammopathy, highlighting the diagnostic challenges posed by this disease and reviewing the diagnostic role of (18) F-FDG PET/CT in POEMS syndrome.
\end{abstract}

\section{Introduction}

POEMS syndrome is a rare paraneoplastic syndrome driven by neoplastic plasma cells. Diagnosis is often delayed as the syndrome is rare and can be mistaken for other diseases. The diagnosis of POEMS syndrome is confirmed in the presence of two mandatory major criteria (polyneuropathy and clonal plasma cell disorder), one of three other major criteria (sclerotic bone lesions, elevated VEGF, or Castleman disease), and at least one minor criterion [1]. Here, we present a case of POEMS syndrome complicated with Sjögren's syndrome $(\mathrm{SjS})$, with significant initial manifestation of polyneuropathy but without a peripheral monoclonal gammopathy. In this case, making the diagnosis can be challenging, but radiographic examinations and biopsy analysis can help differentiate this syndrome from other conditions. Herein, this paper will review the diagnostic role of (18) F-FDG $\mathrm{PET} / \mathrm{CT}$ in POEMS syndrome.

\section{Case Report}

A 58-year-old male was admitted to our center with a 6month history of progressive numbness and weakness of extremities, complicated with dyspnea and repeated low fever. By a careful review of systems, positive results of eyes and arthralgia of the both knee joints were found. Inspection of his extremities showed noticeable hyperpigmentation. Physical examination showed decreased breath sounds. Neurological examination revealed predominant lower extremity weakness; the motor power in the upper extremities was MRC grade 4+, while the motor power in the lower extremities was MRC grade 4. The sensations of touch, pain, and vibration were decreased by $70 \%$ in the distal part of the extremities, although the position sense was intact. The patient's deep tendon reflexes were decreased. The cerebellar function test and the Romberg test showed no abnormalities. Neurophysiological evaluation revealed a sensory-motor demyelinating polyneuropathy. 
An ophthalmologic examination showed xerophthalmia and papilledema.

Computed tomography (CT) showed bilateral pleural effusions. Ultrasonography showed splenomegaly and subaxile lymphadenectasis. Besides, echocardiography and electrocardiogram findings were normal. Pulmonary function test indicated restrictive lung disease and reduced diffusing capacity of the lung for carbon dioxide (DLCO). Major laboratory results were shown in Table 1 . The spinal fluid demonstrated markedly elevated protein level $(1.13 \mathrm{~g} / \mathrm{L}$, normal range: $0.15-0.45 \mathrm{~g} / \mathrm{L})$. Pleural effusion analysis was normal, and no malignant cell was detected by a cytology exam. No infection evidence was found following repeated cultures of blood, pleural effusion, and cerebrospinal fluid. T-spot, procalcitonin, galactomannan (GM) antigen detection, or latex agglutination test was negative. Extensive immunologic testing was unremarkable. Bence Jones protein test result was negative. Repeated serum and urine immunofixation revealed no monoclonal gammopathy. There was no elevation of free kappa and lambda light chain in serum or urine, also with the normal light chain ratio (Table 1). Thyroid function tests revealed hypothyroidism (Table 1); however, the antibodies against thyroglobulin, thyroid peroxidase, or thyroid stimulating hormone (TSH) receptor were all negative, and the thyroid ultrasound showed normal results. Salivary gland scintigraphy with technetium revealed the reduction of radiotracer uptake and intake in gland. Biopsy of a minor labial gland showed typical lymphocytic infiltrates. Therefore, a diagnosis of primary Sjögren's syndrome ( $\mathrm{SjS}$ ) was confirmed following the positive findings including dry eyes, positive salivary scintigraphy, ocular staining score $\geqq 3$, and histopathological evidences (focus score, $\geqq 1$ focus $/ 4 \mathrm{~mm}^{2}$ ), according to 2012 American College of Rheumatology (ACR) classification criteria for Sjögren's syndrome [2]. The patient's thyroid function returned to be normal after treating with Levothyroxine. Considering that his polyneuropathy was due to $\mathrm{SjS}$, he was treated with methylprednisolone $(120 \mathrm{mg} / \mathrm{d})$ and IVIg for 3 days, and the dose of methylprednisolone was tapered to $60 \mathrm{mg} / \mathrm{d}$. His temperature was back to normal then, but his paresthesia and weakness in extremities were not relieved remarkably.

Magnetic resonance imaging (MRI) of the spine revealed a bone lesion in the body of T12, measuring about $21.1 \mathrm{~mm}$ (Figure 1). (18) F-FDG PET/CT showed an isolated osteosclerotic bone lesion in T12 with the increased FDG uptake (the average SUV is 12.4) (Figure 1). Histological examinations of the bone lesion biopsy showed plasmacytoma with predominance of lambda light chain expression in the plasma cell aggregates (Figure 2). Additionally, the immunohistochemical examination revealed CD38 (++), CD138 (++), CD56 (-), CD117 ( \pm$)$, CD20 (-), Cyclin D1 ( \pm$)$, MUM-1 (+), kappa (-), lambda $(++), \operatorname{Bcl}-2( \pm), \mathrm{Ki}-67(<1 \%$ positive), EMA $(+)$, and CD19 (-). Cytological and histological examination of the bone marrow showed no proliferation of plasma cells. Serum VEGF level was highly elevated ( $>800 \mathrm{pg} / \mathrm{mL}$, normal range: $0 \sim 142)$. POEMS syndrome secondary to solitary plasmocytoma was diagnosed based on polyneuropathy, splenomegaly, hypogonadism, plasmacytoma, osteosclerotic bone lesion,
TABLE 1: Laboratory results.

\begin{tabular}{|c|c|}
\hline Variable & Value (normal range) \\
\hline Hemoglobin, g/L & $164(130-175)$ \\
\hline White blood cell count, $\times 10^{9} / \mathrm{L}$ & $6.43(3.5-9.5)$ \\
\hline Neutrophil, $\times 10^{9} / \mathrm{L}$ & $4.12(1.8-6.3)$ \\
\hline Platelet count, $\times 10^{9} / \mathrm{L}$ & $163(125-350)$ \\
\hline Creatinine, serum (SCr), umol/L & $90(59-104)$ \\
\hline Albumin, g/L & $35.5(40-55)$ \\
\hline Alanine transaminase (ALT), U/L & $29(9-50)$ \\
\hline Aspartate aminotransferase (AST), U/L & $24(15-40)$ \\
\hline Prothrombin time (PT), sec & $11.7(9.6-12.2)$ \\
\hline $\begin{array}{l}\text { Activated partial thromboplastin time } \\
\text { (APTT), sec }\end{array}$ & $27.4(20.3-32.3)$ \\
\hline D-Dimer, FEU mg/L & $0.60(<0.55)$ \\
\hline Immunoglobulin (Ig) G, g/L & $23.4(7-16)$ \\
\hline $\operatorname{IgM}, g / L$ & $0.58(0.4-2.30)$ \\
\hline $\operatorname{IgA}, g / L$ & $0.92(0.7-4.0)$ \\
\hline Serum kappa, mg/L & $3.31(1.7-3.7)$ \\
\hline Serum lambda, mg/L & $1.78(0.90-2.10)$ \\
\hline Serum kappa/lambda & $1.85(1.35-2.65)$ \\
\hline Urine kappa, mg/L & $2.10(<4.10)$ \\
\hline Urine lambda, mg/L & $1.69(<7.50)$ \\
\hline Urine kappa/lambda & $1.24(0.70-4.5)$ \\
\hline Creatine phosphokinase (CPK), U/L & $13(39-308)$ \\
\hline $\begin{array}{l}\text { Probrain natriuretic peptide (BNP), } \\
\mathrm{pg} / \mathrm{mL}\end{array}$ & $1393(0-210)$ \\
\hline Lactate dehydrogenase (LDH), U/L & $181(135-225)$ \\
\hline Testosterone, $\mathrm{nmol} / \mathrm{L}$ & $4.21(6.68-25.70)$ \\
\hline Dehydroepiandrosterone, umol/L & $0.27(1.91-13.4)$ \\
\hline $\begin{array}{l}\text { Thyroid stimulating hormone (TSH), } \\
\text { mIU/L }\end{array}$ & $11.99(0.34-5.60)$ \\
\hline Free triiodothyronine (FT3), pmol/L & $2.40(3.80-6.00)$ \\
\hline Free thyroxine (FT4), pmol/L & $8.67(7.86-21.10)$ \\
\hline Free cortisol in urine, ug/24 h & $412.17(30.15-129.13)$ \\
\hline Serum calcium, mmol/L & $2.16(2.15-2.50)$ \\
\hline Beta 2-microglobulin, mg/L & $4.48(0.9-3.10)$ \\
\hline $\begin{array}{l}\text { Vascular endothelial growth factor } \\
\text { (VEGF), pg/mL }\end{array}$ & $>800(0-142)$ \\
\hline $\begin{array}{l}\text { Cerebrospinal fluid (CSF) glucose, } \\
\mathrm{mmol} / \mathrm{L}\end{array}$ & $4.28(2.22-3.89)$ \\
\hline Cerebrospinal fluid (CSF) protein, g/L & $1.13(0.15-0.45)$ \\
\hline $\begin{array}{l}\text { Cerebrospinal fluid (CSF) chloridum, } \\
\mathrm{mmol} / \mathrm{L}\end{array}$ & $126(120-132)$ \\
\hline Cerebrospinal fluid (CSF) Pandy's test & $2+$ \\
\hline $\begin{array}{l}\text { Cerebrospinal fluid (CSF) white blood } \\
\text { cell, } 10^{6} / \mathrm{L}\end{array}$ & $0(0-8)$ \\
\hline $\begin{array}{l}\text { Cerebrospinal fluid (CSF) red blood cell, } \\
10^{6} / \mathrm{L}\end{array}$ & 2 \\
\hline
\end{tabular}




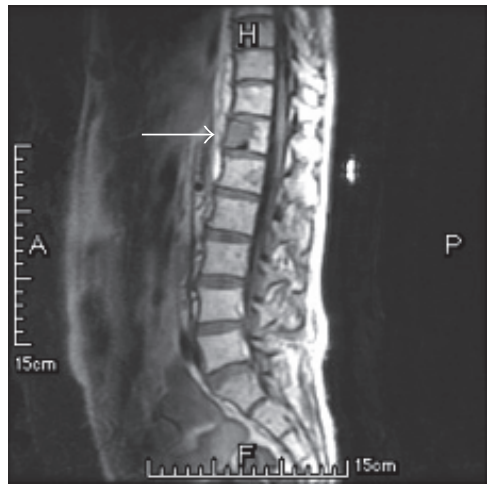

(a)

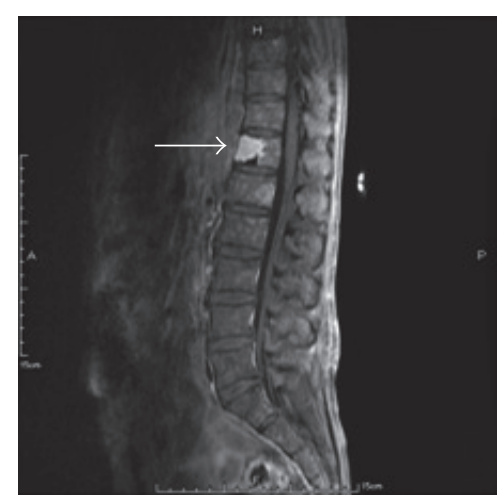

(b)

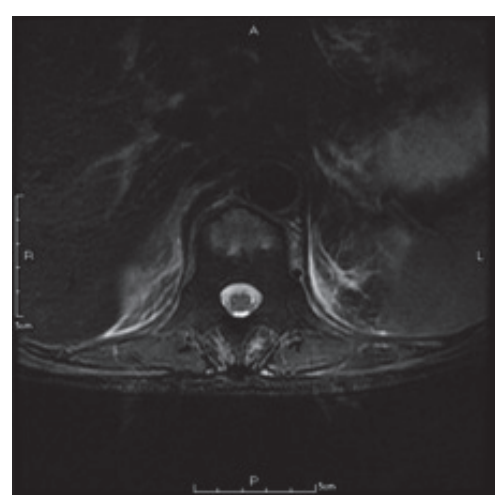

(c)

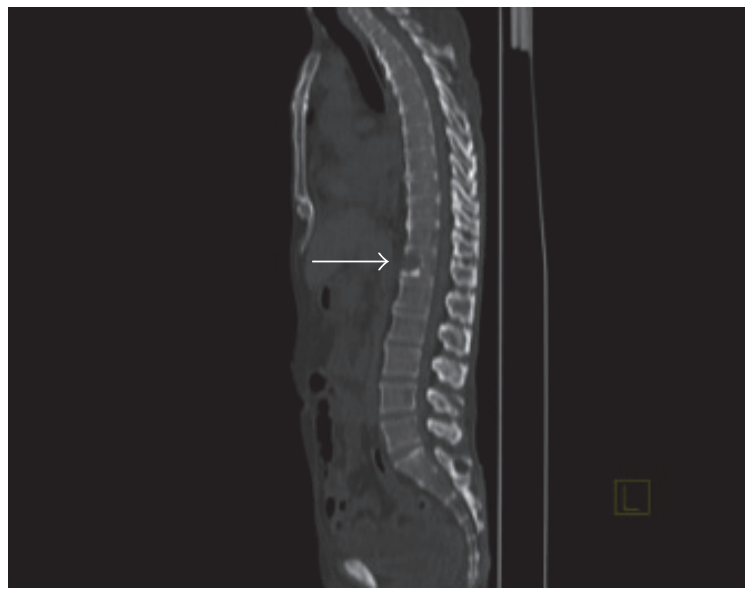

(d)

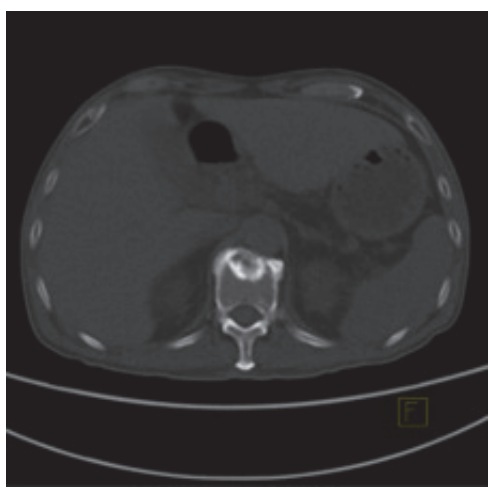

(f)

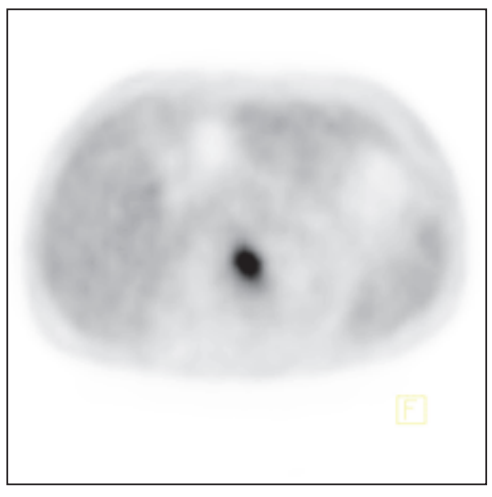

(g)

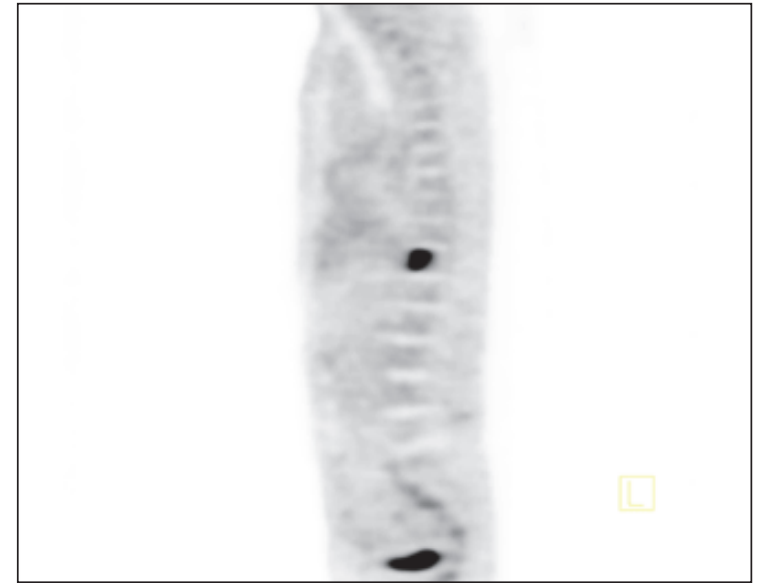

(e)

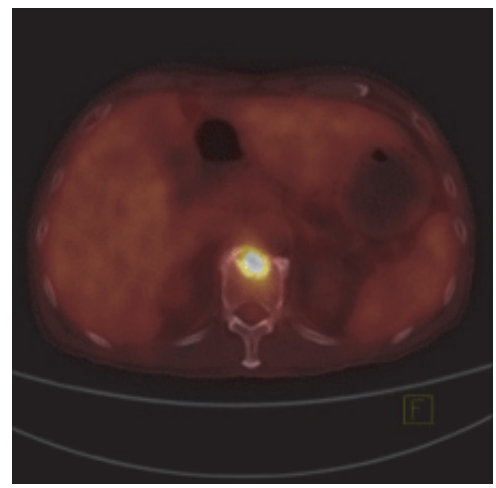

(h)

FIGURE 1: Images of the bone lesion detected by MRI and (18) F-FDG PET/CT. (a) (c): Short-tau inversion-recovery (STIR) sequence in MRI shows a bone lesion in T12 vertebra, with T1-hypointense and T2-hyperintense signal. (a) Sagittal TI STIR image. (b) Sagittal T2 STIR image. (c) Transaxial T2 STIR image. (d) (h): (18) F-FDG PET/CT image shows an osteosclerotic lesion, with hypermetabolism in T12 vertebra. (d) Sagittal CT image. (e) Sagittal PET image. (f) Transaxial CT image with a significant sclerotic ring around the bone lesion. (g) Transaxial PET image with an average SUV value of 12.4. (h) Fused PET/CT image.

VEGF elevation, pleural effusion, and skin changes, which were consistent with the proposed diagnostic criteria [1]. The patient died of rapid disease progression of polyserositis before starting radiotherapy.

\section{Discussion}

The challenges in diagnosing this case lied in (1) the overlapping manifestation of polyneuropathy in POEMS syndrome 


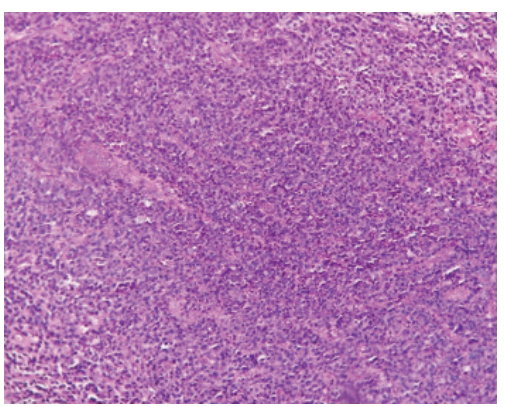

(a)

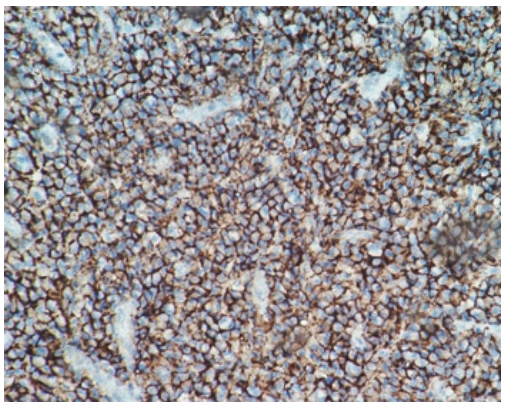

(d)

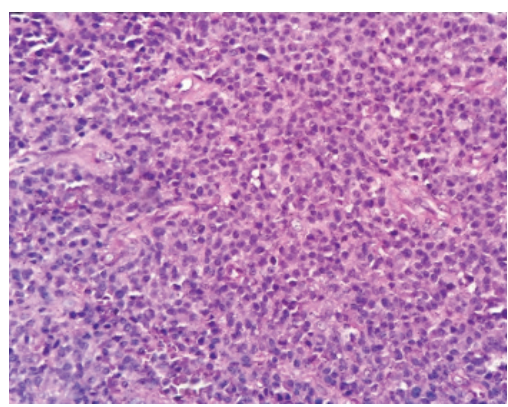

(b)

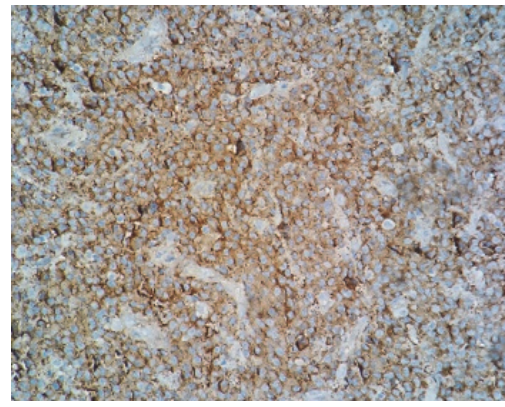

(e)

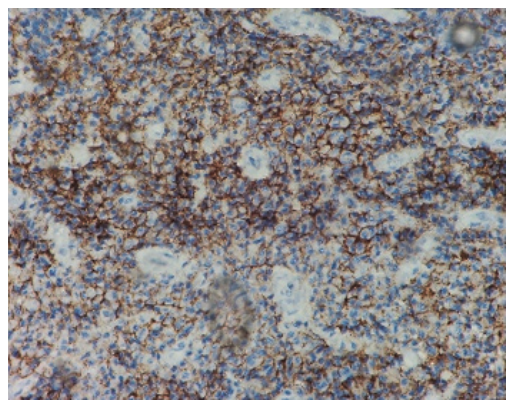

(c)

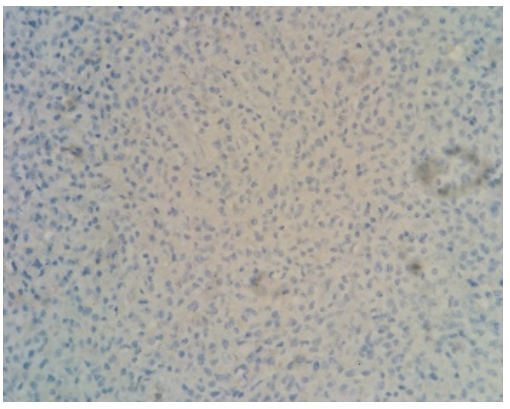

(f)

FIgURE 2: Histological analysis of the bone lesion in the body of T12. (a) The micrograph shows the accumulation of plasma cells with the destruction of trabecular bones [hematoxylin and eosin (H\&E) staining; magnification, $\times 200$ ]. (b) Higher magnification of the image in (a) (H\&E staining; magnification, $\times 400)$. Immunohistochemical staining shows positive expression of (c) CD38 (++), (d) CD138 (++), (e) lambda (++), and (f) kappa (-) (magnification, $\times 400)$.

and $\mathrm{SjS}$ and (2) the undetectable monoclonal gammopathy. POEMS syndrome is a rare variant of plasma cell neoplasm. Nonsecretory plasmacytoma is also a rare form of plasmacytoma characterized by the absence of detectable monoclonal gammopathy in serum and urine. Misdiagnosing or mislabeling the patients with plasmacytoma results in the delay of their urgent treatments. In this case, comprehensive imaging studies and histopathologic confirmation are necessary.

Firstly, we will analyze and compare the peripheral neuropathy patterns in POEMS syndrome and SjS. Demyelinating polyneuropathy is a typical characteristic of POEMS syndrome; also it is a mandatory major criterion for diagnosing POEMS. Endothelial injury is a leading cause in the progression of polyneuropathy in POEMS syndrome, and the overproduction of VEGF enhances microvascular permeability and subsequent endoneurial edema $[8,9]$. No direct correlation has been observed between the levels of monoclonal gammopathy and the severity of neuropathy. Although our patient did not have a demonstrable paraprotein, he had a proven plasmacytoma with lambda light chain clonality, which has been reported in previous literature regarding POEMS $[10,11]$. Based on the extent of the plasma cell infiltration, targeting therapy at the underlying clonal plasma cell could improve symptoms and even cure the patients [1]. In this case, since the patient had a solitary plasmacytoma without clonal plasma cells found in bone marrow biopsy, radiation is the recommended therapy [1]; however, he had no chance for radiotherapy.
The prevalence of $\mathrm{SjS}$ associated peripheral neuropathy is reported in recent studies, ranging from $2 \%$ to over $60 \%[12,13]$. The clinical spectrum of peripheral neurologic involvement in SjS is wide, and all segments of peripheral nervous system can be involved, with sensory neuropathies being the most common $[12,13]$. Cranial neuropathy, multiple mononeuropathy, demyelinating polyneuropathy, and autonomic neuropathy are less frequently encountered types $[12,13]$. Autoimmunity induced vasculitis and autoantibodies are thought to be the contributors in the pathogenesis of $\mathrm{SjS}$ associated polyneuropathies [14]. Demyelinating polyneuropathies have been reported in some cases $[12,13,15]$. This type of neuropathy is usually much severer and typically presents with proximal and distal weakness and sensory deficits with subacute onset. Cerebrospinal fluid studies reveal elevated protein level with normal cell count, while the neurophysiological evaluation shows the typical demyelination changes [16]. Prompt treatment with steroids and IVIg is reported to be an effective therapeutic intervention for this type of neuropathy $[16,17]$.

Secondly, we will review the diagnostic role of (18) F-FDG $\mathrm{PET} / \mathrm{CT}$ in POEMS syndrome. In this case, MRI detected the bone lesion but not revealing the typical sclerotic property; CT revealed an osteosclerotic lesion; (18) F-FDG PET/CT confirmed its superiority in defining both skeletal lesions and the activity of the neoplastic process. We herein conclude that the different manifestations of the disease imply the necessity of a complex evaluation of imaging methods in 
TABLE 2: Clinical characteristics of POEMS cases in published reports.

\begin{tabular}{|c|c|c|c|c|c|c|}
\hline Author and reference & $\begin{array}{l}\text { Year of } \\
\text { study }\end{array}$ & Study design & $\begin{array}{l}\text { Number of } \\
\text { POEMS } \\
\text { patients }\end{array}$ & $\begin{array}{c}\text { Technical procedure } \\
\text { used }\end{array}$ & $\begin{array}{l}\text { Other diagnostic } \\
\text { images }\end{array}$ & Primary outcome \\
\hline Glazebrook et al. [3] & 2015 & $\begin{array}{l}\text { Retrospective } \\
\text { clinical study }\end{array}$ & 24 & (18) F-FDG PET/CT & $\mathrm{X}$-ray and CT & Diagnosis \\
\hline Royer et al. [4] & 2013 & $\begin{array}{l}\text { Retrospective } \\
\text { clinical study }\end{array}$ & 12 & (18) F-FDG PET/CT & $\mathrm{X}$-ray and CT & $\begin{array}{c}\text { Diagnosis (11/12 } \\
\text { patients have positive } \\
\text { findings); evaluation } \\
\text { of clinical response to } \\
\text { therapies }\end{array}$ \\
\hline Minarik et al. [5] & 2012 & Case report & 3 & (18) F-FDG PET/CT & $\begin{array}{c}\text { X-ray, CT, } \\
\text { technetium } \\
\text { scintigraphy, MRI, } \\
\text { and angiography }\end{array}$ & Diagnosis \\
\hline Montoriol et al. [6] & 2011 & Case report & 2 & (18) F-FDG PET/CT & $\begin{array}{l}\text { X-ray, CT, MRI, } \\
\text { and technetium } \\
\text { scintigraphy }\end{array}$ & Diagnosis \\
\hline Albertí et al. [7] & 2010 & Case report & 4 & (18) F-FDG PET/CT & $\begin{array}{l}\text { X-ray, CT, and } \\
\text { technetium } \\
\text { scintigraphy }\end{array}$ & Diagnosis \\
\hline
\end{tabular}

mutual concordance. (18) F-FDG PET/CT emerges as the most contributive method for evaluating both the extent and the activity of this disease (Table 2).

POEMS syndrome presents with a constellation of signs and symptoms that may lead a clinician to a multitude of other possible diagnosis. There exist overlapping clinical signs between POEMS and SjS, and confirmed diagnosis can be made based on detailed clinical history, physical examination, imaging tests, and biopsy analysis.

\section{Competing Interests}

The authors have no competing interests to declare.

\section{Authors' Contributions}

All authors contributed to the design of the study, the analysis of data, and the writing of the manuscript. Each author reviewed the final version of the manuscript and approved it for publication. Weiguo Wan and Jun Liu contributed equally to this work.

\section{Acknowledgments}

This work was supported by the National Natural Science Foundation of China Grant 81501391 (to Minrui Liang) and by Huaxiu Award 687 (to Minrui Liang).

\section{References}

[1] A. Dispenzieri, "POEMS syndrome: 2014 update on diagnosis, risk-stratification, and management," American Journal of Hematology, vol. 89, no. 2, pp. 214-223, 2014.

[2] S. C. Shiboski, C. H. Shiboski, L. Criswell et al., "American College of Rheumatology classification criteria for Sjogren's syndrome: a data-driven, expert consensus approach in the
Sjogren's International Collaborative Clinical Alliance cohort," Arthritis Care \& Research, vol. 64, no. 4, pp. 475-487, 2012.

[3] K. Glazebrook, F. L. Guerra Bonilla, A. Johnson, S. Leng, and A. Dispenzieri, "Computed tomography assessment of bone lesions in patients with POEMS syndrome," European Radiology, vol. 25, no. 2, pp. 497-504, 2015.

[4] B. Royer, L. Merlusca, J. Abraham et al., "Efficacy of lenalidomide in POEMS syndrome: a retrospective study of 20 patients," American Journal of Hematology, vol. 88, no. 3, pp. 207-212, 2013.

[5] J. Minarik, V. Scudla, J. Bacovsky et al., "Comparison of imaging methods in POEMS syndrome," Biomedical Papers, vol. 156, no. 1, pp. 52-57, 2012.

[6] P. F. Montoriol, F. Cachin, J. L. Michel, and M. Soubrier, "Two more cases of evaluation of POEMS syndrome using 18-FDG PET/CT,' European Journal of Radiology, vol. 80, no. 3, pp. 861864, 2011.

[7] M. A. Albertí, S. Martinez-Yélamos, A. Fernandez et al., "18F-FDG PET/CT in the evaluation of POEMS syndrome," European Journal of Radiology, vol. 76, no. 2, pp. 180-182, 2010.

[8] K. Saida, H. Kawakami, M. Ohta, and K. Iwamura, "Coagulation and vascular abnormalities in Crow-Fukase syndrome," Muscle \& Nerve, vol. 20, no. 4, pp. 486-492, 1997.

[9] M. Scarlato, S. C. Previtali, M. Carpo et al., "Polyneuropathy in POEMS syndrome: role of angiogenic factors in the pathogenesis," Brain, vol. 128, no. 8, pp. 1911-1920, 2005.

[10] T. Stankowski-Drengler, M. A. Gertz, J. A. Katzmann et al., "Serum immunoglobulin free light chain measurements and heavy chain isotype usage provide insight into disease biology in patients with POEMS syndrome," American Journal of Hematology, vol. 85, no. 6, pp. 431-434, 2010.

[11] M. J. Brewis, A. C. Church, A. J. Peacock, S. Thomson, J. Tighe, and M. K. Johnson, "Pulmonary hypertension in POEMS syndrome: resolution following radiotherapy," Pulmonary Circulation, vol. 4, no. 4, pp. 732-735, 2014.

[12] I. A. Grant, G. G. Hunder, H. A. Homburger, and P. J. Dyck, "Peripheral neuropathy associated with sicca complex," Neurology, vol. 48, no. 4, pp. 855-862, 1997. 
[13] K. Mori, M. Iijima, H. Koike et al., "The wide spectrum of clinical manifestations in Sjögren's syndrome-associated neuropathy," Brain, vol. 128, no. 11, pp. 2518-2534, 2005.

[14] P. Brito-Zerón, M. Akasbi, X. Bosch et al., "Classification and characterisation of peripheral neuropathies in 102 patients with primary Sjögren's syndrome," Clinical and Experimental Rheumatology, vol. 31, no. 1, pp. 103-110, 2013.

[15] S. Delalande, J. de Seze, A.-L. Fauchais et al., "Neurologic manifestations in primary Sjögren syndrome: a study of 82 patients," Medicine, vol. 83, no. 5, pp. 280-291, 2004.

[16] P. P. Pavlakis, H. Alexopoulos, M. L. Kosmidis et al., "Peripheral neuropathies in Sjögren's syndrome: a critical update on clinical features and pathogenetic mechanisms," Journal of Autoimmunity, vol. 39, no. 1-2, pp. 27-33, 2012.

[17] M. C. Dalakas, "Advances in the diagnosis, pathogenesis and treatment of CIDP," Nature Reviews Neurology, vol. 7, no. 9, pp. 507-517, 2011. 


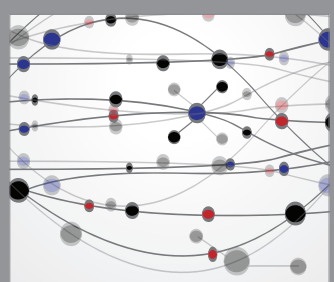

The Scientific World Journal
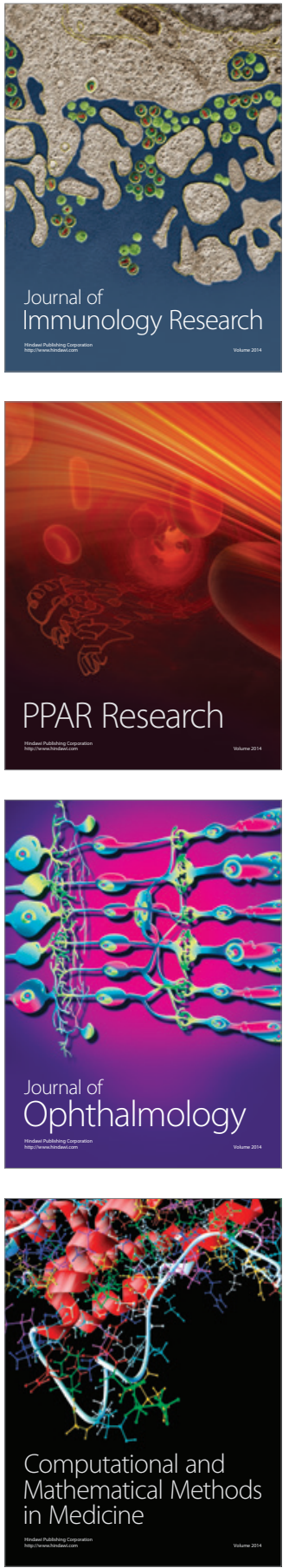

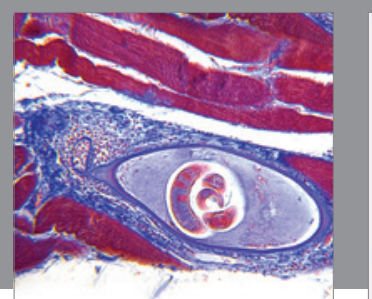

Gastroenterology Research and Practice
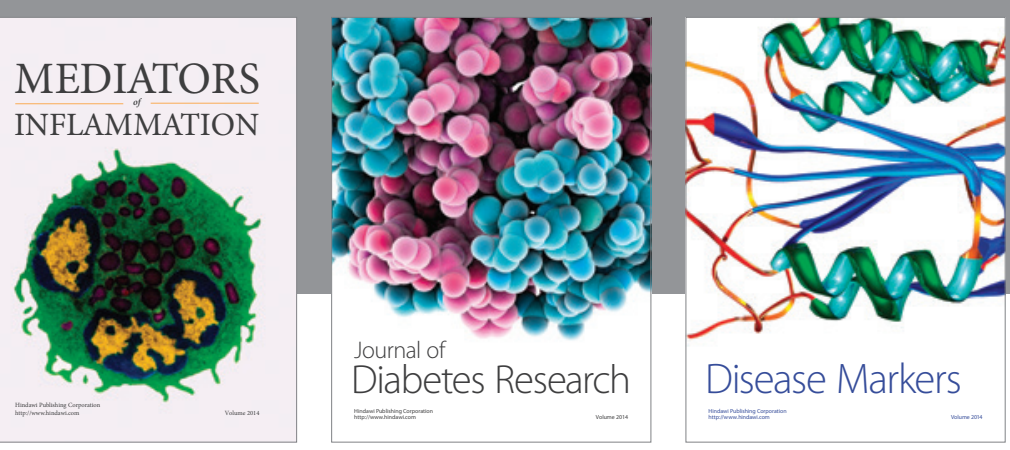

Disease Markers

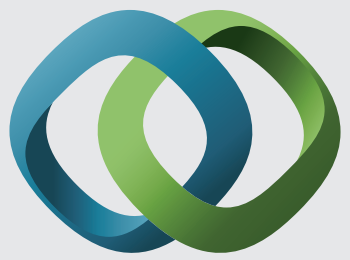

\section{Hindawi}

Submit your manuscripts at

https://www.hindawi.com
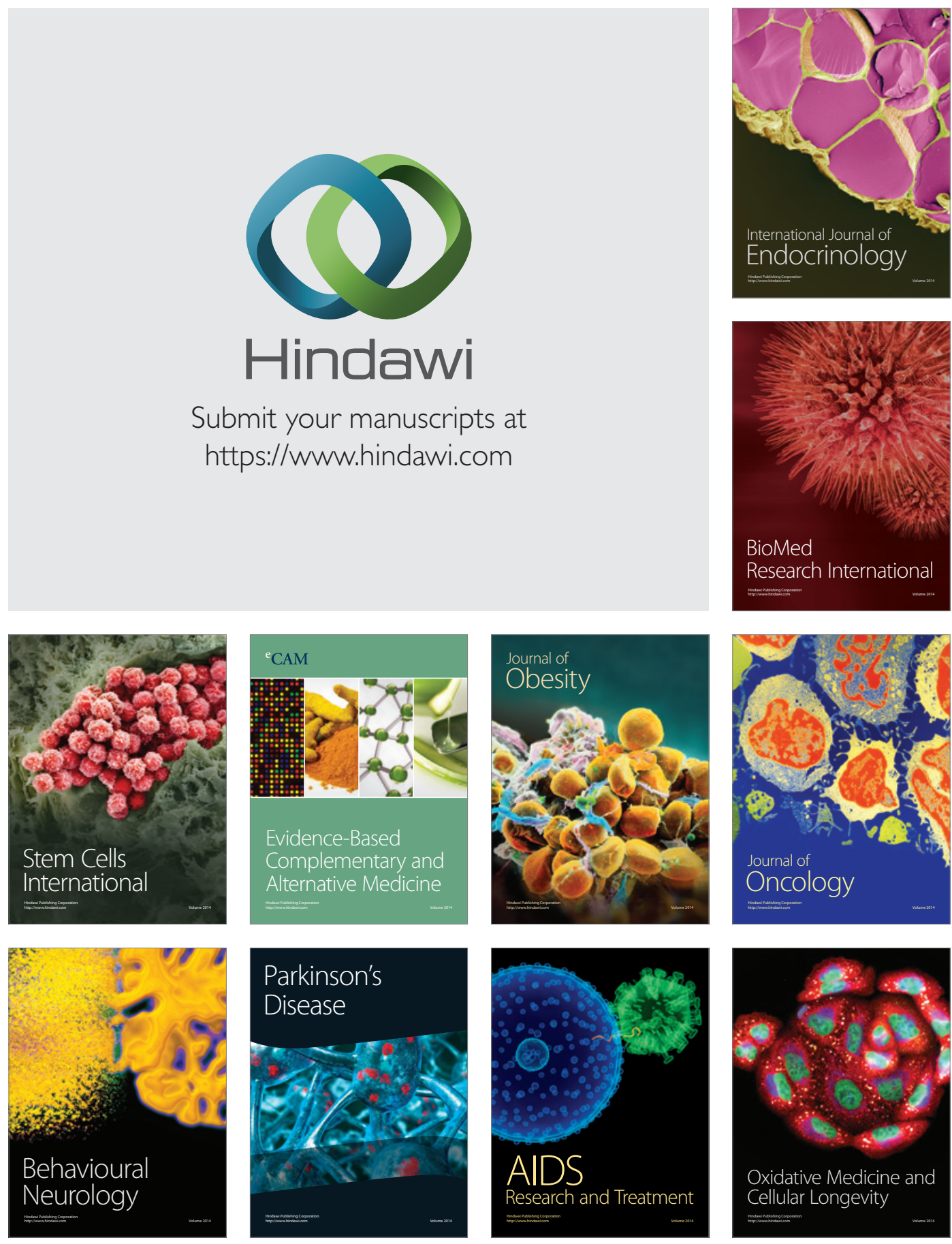